\title{
HUMAN CAPITAL - THE EFFECTS OF EDUCATION ON ECONOMIC GROWTH WITHIN THE EUROPEAN UNION
}

\author{
Pribac Loredana PhD \\ "Vasile Goldis" Western University of Arad \\ pribacloredana@yahoo.com \\ Professor Anghelina Andrei PhD \\ "Vasile Goldis" Western University of Arad \\ a_anghelina@uvvg.ro
}

(Received June 2015; accepted August 2015)

\begin{abstract}
Human capital has an impact on economic growth by several channels. This study presents a conceptual research model that we built starting from the economic increase models which explain the way in which the revenue per inhabitant was created taking into account mechanisms, channels and influence factors. I applied this model to the member states of the European Union and the results obtained confirmed the existence of some positive effects of human capital - expressed through education - on economic growth.
\end{abstract}

Key words: human capital, education, economic growth, EU

J.E.L. CODES: O40, I25

\section{Introduction}

Empirical studies developed on this issue did not reach a consensus regarding the decisive role of education in the growth process, certain authors manifesting uncertainty or limiting this role, especially according to the sample of analyzed countries, to the measures of approximating the human capital, the considered period, the data bases used, the multitude of variables introduced within the models, the estimation methods etc.

However, one may outline many analyses and econometric models, which support the positive influence of education in the growth process, and, starting from such models considered relevant, we created a conceptual model of research, which comprises the theoretical and empirical elements that we used for the grounding of our empirical study, respectively the estimation models, the influence variables and their measures, as well as the methods that we selected and suggested in assessing the analyzed relation.

The objective of this study is to present Schematic channels through which education affects economic growth. We also presented summaries of the results obtained from research conducted on this topic. 


\section{Human capital - impact channels of education on economic growth}

Human capital, as an assembly of the knowledge, abilities, skills of any individual, in a word of the individuals' capacities valuated on the labour market which lead to the increase of their productive efficacy, has an impact on the economic growth through several channels. According to theory, the factors that may directly influence productivity are related to:

- the high quality of the labour force, respectively the higher knowledge of individuals (especially the know-how in what concerns the new technologies) makes their work more productive (investments for improving the quality of the educational system, as well as the increase of the comprehension and knowledge in mathematics and other sciences, lead to the increase of the individuals' productivity),

- the more productive use of capital as compared to the prior productions, respectively the increase of the capital volume per worker frequently measured by the capital stock in relation to one working hour. Economy on the whole, will develop and productivity per worker will increase,

- innovation, involving the creation of new products, also by developing those which already exist, but also by adopting new technologies, results of the research activity, is the means by which the productive capacity of the labour force increases.

Starting from the diagram suggested by Katharina Michaelowa (2000), from the initiative of Denise Hawkes and Mehmet Ugur (2012), the main channels by which one can highlight the impact of education on economic growth lead to the formation of a conceptual model that we later used in the operationalization of our empirical approach (Figure no. 1).

Literature also describes the relationship between education and individual revenues by the fact that the results of education represent new skills and new knowledge, which increase productivity: if workers are paid according to the value of their marginal product, better-educated workers should get higher revenues (salaries).

Better-educated labour force is a factor for attracting new foreign direct investments, which involves the development of activities, which lead to the increase in the demand for labour force. Equally, export is interpreted as a marker of the expansion of the demand for qualified labour force (Psacharopoulos, 2007). What do all of these mean? An increased participation of the labour force in the labour market.

Besides the direct effects of education on people's revenues, education influences other variables with impact on the individual revenue, this effect regarding not only the educated person, but other people too (who belong to a higher or lower extent to the circles of the people having higher education and better skills). In this 
direction, a series of specific externalities are obvious, such as the impact of the family, parent's education, which may constitute a significant factor in improving children's health and education (Michaelowa, 2000). Also, people who have a better education may convey information with impact on various decisions related to health (we notice, for instance, an influence in that what represents the decrease of the fertility rate / undesired pregnancies).

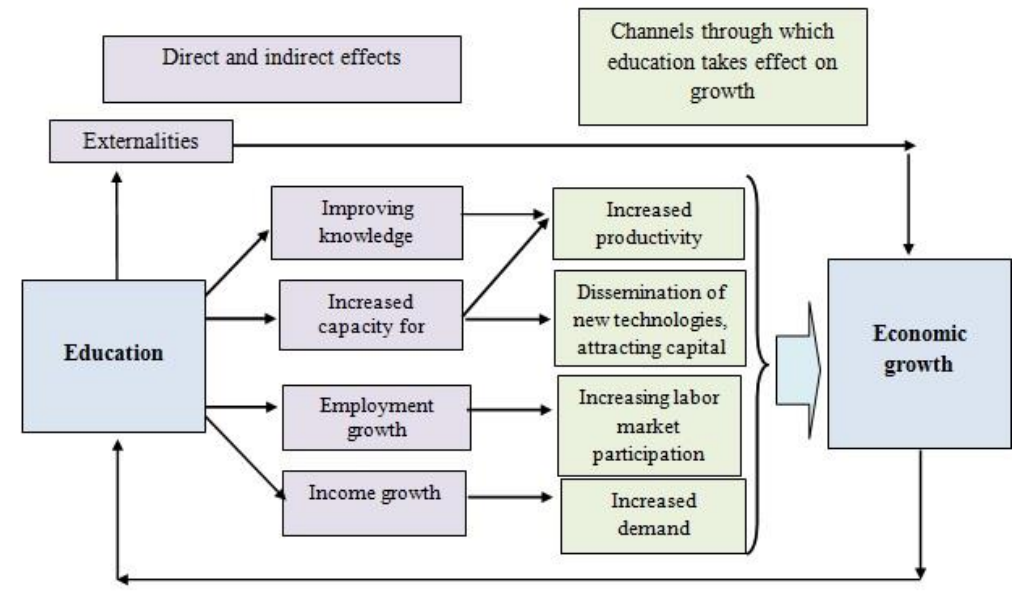

Figure no. 1. Conceptual Model Research

Source: worked up Michaelowa, Katharina. (2000) "Returns to Education in Low Income Countries: Evidence for Africa." and Denise Hawkes, Mehmet Ugur (2012) "Evidence on the relationship between education, skills and economic growth in low-income countries: A systematic review". London: EPPI-Centre, Social Science Research Unit, Institute of Education, University of London

All these ways of connecting the effects on the increase are reflected by the growth theories, being at the same time pointed out by the very numerous empirical studies from economic literature. Nevertheless, there are big differences in appreciating these models, even if, generally speaking, literature is in favour of the role of education on the increase of capital per worker. Thus, if according to Solow, increase stops when economy reaches the stationary equilibrium condition, new investments being required which enable the increase of the capital quantity available for each worker, according to the endogenous models, the gathering of capital might lead to a sustainable economic growth. In this direction, we would like to mention the models of MRW (1992), of Islam (1995) etc.. Equally, the link between education and salaries is widely debated, and it is found in the models whose results are very consistent, showing clear positive effects, not only from a macroeconomic, but also from a microeconomic point of view (for example, Mincer's model etc.). 


\section{The methodological approach}

Our methodological approach consists of establishing the conceptual frame of analysis, starting from the neoclassical- and endogenous-like economic growth models, which explain the way in which the increase of the revenues per inhabitant is achieved, taking into account the mechanisms, the channels, the influence factors (Picture 1.). In our case, what we aimed at was to point out the theoretical fundaments of the causal relation between education - by which we expressed human capital - and economic growth.

Within the specifications of the models used, we linked the variable to be explained with the markers inserted in the models, as measures of the variables independent on influence. Human capital is represented by a variable whose measurement has multiple capacities, very difficult to be achieved with precision, especially, on long periods of time and for different countries. Thus, after having suggested the analysis patterns, the description of the significance and the way of calculating the variables, in view of carrying out the empirical research, we built the database corresponding to the estimation markers of the influence variables, using national and international data for comparability between countries. In view of operationalizing the considered models we presented the econometric models and methods of assessment and testing of the specifications' validity and of the estimates' significance degree. Based on them, we initiated the empirical approach starting from a statistical analysis of the models' variables and, at the same time, from that of some defining markers of the level and quality of education, in connection with the GDP per capita.

The empirical analysis based on a model of multi-factorial linear regression. The analysis of the linear relation between the dependent variable and one or more independent variables has as aim to explain and foresee the variation of the dependent variable in accordance with the independent variables. The robustness and compatibility of the results obtained are appreciated according to the sign and the size of the estimated parameters. The statistical significance of the parameters derives from ensuring that the variation of the dependent variable is not hazardous, but is the result of one or several independent variables.

The general form of the multiple regression model is:

$$
\mathrm{y}=\alpha+\beta_{1} \mathrm{x}_{1}+\beta_{2} \mathrm{x}_{2}+\ldots+\beta_{\mathrm{i}} \mathrm{x}_{\mathrm{i}}+\varepsilon_{\mathrm{i}}
$$

where: $\mathrm{y}$ represents the dependent variable; $\alpha$ is the free term, $\mathrm{x}$ stands for the independent variables, $\beta$ represents the estimated coefficients of the $\mathrm{x}$ variable and $\varepsilon$ is the measuring error.

The hypotheses of the linear model are the following:

I.1: The residual variables of multiple regression have the mean zero: $\mathrm{E}(\varepsilon i)=0$; 
I.2: The residual variables are not linked: $\operatorname{cov}(\varepsilon i, \varepsilon j)=0, i \neq j$

I.3: The homoscedasticity of regression: $\mathrm{E}\left(\varepsilon \varepsilon^{\prime}\right)=\sigma_{\varepsilon}^{2} \mathrm{In}$

In - Matrix of order $n$

I.4: The residual variables are not linked with the variable $\mathrm{x}$ and have the mean zero: $\operatorname{cov}(\mathrm{x}, \varepsilon)=0$. (Andrei, Stancu and Pele, 2002, p. 370-372)

Macroeconomic data used in the research were taken from the following databases: Eurostat (2012), Statistics, Education, PISA, United Nations, Population Division (2012) and Barro \& Lee Databases.

\section{The results of analysis models the economic effects of education on economic growth}

The country and variable samples that we employed within our empirical analysis, starting from the basic models found in literature, as well as by proposing other analysis specifications, are comprised within the research conceptual model. Besides the main variables used within the specifications of the implemented models, it also highlights the country samples that the models' equations specifications were built on, as well as the type of data used in the analysis.

This way, the analysis performed within the research is focused on the correlation between the human capital and the economic growth within the following state groups:

-The EU member states, EU-27, respectively all member states of the Community, over a period comprised between 1990-2009;

-The EU member states, EU-17, including the older 15 member states of the EU, to which we added Cyprus and Malta (states that were not part of the ex-communist bloc, even if they joined in 2004), for the period 1990-2009;

-The older member states of the European Union, EU-15 for the same period;

-The older member states of the European Union, EU-10, respectively both the eight states that joined the EU in 2004, as well as Bulgaria and Romania, which became members in 2007; the analysis period is identical;

-The group of the eight member states of the European Union, that were part of the countries having centralised economy, EU-8, for the period 1990-2009, without Romania and Bulgaria;

-The country group consisting of Bulgaria and Romania, EU-2, 1990-2009.

Separated estimated models for Romania, on macroeconomic specification, for the years 1990-2009 and on microeconomic specification, for the period 1960-2010, according to data series from 5 to 5 years.

These country groups were chosen given the direct interest related to Romania and to the way in which the production factor regarding the human capital has a major impact on growth; during the period which the analysis was made for it suffered 
great changes by the economic policies measures (changes which can also be found in the present member states of the European Union).

Human capital was estimated within models according to several variables; in Annex 1 there can be seen the values of the coefficients obtained for all of these variables, for all the country groups.

Human capital estimated as the product between the ratio of inclusion in education at secondary level of the population between the age of 15-19 and the weight of this population group in the total population has in the case of six country groups the statistical significance at the level of $0.1 \%$ (only for the EU15 group the significance level is of $1 \%$ ), but for all country groups of the European Union the coefficient sign is negative, so the influence on the GDP per capita is not a favourable one.

Contrary to these results are the results obtained for the product between the rate of enrolment of the population between the age of 20-24 in the tertiary education system and the weight of this population in the total population, which has a positive sign of the coefficients; consequently the effect on the GDP per capita is a positive one for all of the seven country groups. From the point of view of the statistical significance, it is at the level of $0.1 \%$.

The variable of the human capital expressed by the weighted mean of the enrolment rate in the education system of the whole population has the maximum statistical significance at the level of $0.1 \%$ for the following country groups: EU27, EU17, EU10 and Romania, at the level of 1\% for EU8 and at the level of $5 \%$ for EU15. All coefficients of the human capital have positive values; consequently, they lead to the increase in the GDP per capita. As far as Romania is concerned, the value of the coefficient is supra-unitary, indicating a greater increase of the GDP per capita as compared with the other country groups.

The coefficients of the variable regarding the expenses with the education per pupil have the positive sign for most of the countries, while only for the EU15 group the sign is negative. As a result, this financial variable has a positive influence on the growth rate (exception EU15 where the effect is negative). A statistical significance of the human capital at the level of $0.1 \%$ resulted for EU27, EU17, EU15, EU10 and EU8, and at the level of $1 \%$ for the group EU2 (Romania and Bulgaria). For Romania, the statistical significance of this variable is low, but the effect on the growth rate is positive.

The rate of graduation of the secondary level education by the people in the age groups 20-24 and respectively 25-64 has a relevant statistic significance at the level of $0.1 \%$ and a positive influence (coefficients have the plus sign) on the growth rate, but only for the EU10 countries group.

Human capital expressed by another financial variable (public expenses for education as a percentage from the GDP) leads to an unfavourable effect for the 
growth rate, having the minus sign for the coefficient and a statistic significance of just $5 \%$.

For the dynamic model without lag, in which we used both a quantitative and a qualitative variable for estimating the human capital, the results obtained for the quantitative variable (the mean of the study years on the three levels of education) leads to an indirect positive effect on the growth rate, because the coefficient sign is plus, but the statistical significance is a low one (except for these two country groups: EU17 and EU10). From the point of view of the statistical significance the results obtained for the qualitative variable (the scores obtained in international tests) are much more relevant, thus for EU27 and EU17 the statistical relevance is at $0.1 \%$, for EU15 at $1 \%$, for EU10 at 5\%, and for EU8 the relevance is much lower. Between the values of the coefficients there is a big difference explained by the magnitude of the effect produced on the growth rate, thus the human capital expressed through the qualitative variable leads to a greater increase of the GDP/capita.

In the second dynamic-like model in which the quantitative variable is expressed by the mean of the study years at tertiary level the results indicate a statistical relevance much more significant than in the case of the model which includes the mean of the study years for the three education cycles, thus for EU21, EU17, EU10, the statistical relevance of the variable is at $0.1 \%$, and for EU15 at $1 \%$. The influence of this variable on the growth rate is positive for all the four country groups. The results obtained for the qualitative variable are similar with the ones obtained in the first dynamic type model, which highlights the fact that the estimation of the human capital by a qualitative variable has a positive effect, equal in magnitude on the growth rate, irrespective of the quantitative variable of the human capital.

In the lagged dynamic models, the qualitative variable of the human capital (the scores obtained in the international tests) has a lower statistical significance than in the models without lag; only for EU27 a statistical significance is maintained at 0.1 $\%$. The influence on the GDP per capita is a positive one, but the coefficient values are smaller than in the dynamic models without lag. The quantitative variable of the human capital has the negative sign for the coefficients and a low statistical significance; hence, the effect on the per capita GDP is negative.

For Romania human capital was expressed in accordance with Mincer's specification and it may be noticed that from the point of view of the statistical relevance the variable is significant at the level of $0.1 \%$, in just one out of nine models; however the coefficient values are positive, so the effect on the growth rate is a positive one.

Among all the variables which human capital was estimated through, the most relevant from a statistical point of view and from the point of view of their impact 
on the GDP/capita are: the product between the rate of enrolment in the tertiary education system of the population between 20-24 years of age and the weight of this population in total, the weighted mean of the enrolment rate in the education system of the whole population and the qualitative variable (the scores obtained in the international tests). Consequently, human capital has a significant influence in economic growth, both by some quantitative variables, and more notably by the qualitative ones.

\section{Conclusions}

The very complex aspects on the approached topic from conceptualisation to application also lead to possible technical flaws or general flaws of comprehending such an analysis. The specific situation related to the relatively reduced availability of some exact comparable data for the analysed countries, on series of time, especially on the qualitative dimension of education (and which are essentially linked to objective factors in connection to the small number of international assessment tests which the pupils from the considered countries participated in and only recent date ones) creates difficulties in correctly estimating the growth regressions, with direct implications on some errors in the results obtained. Equally, the possibility of validating just certain specifications - a consequence of the available measures for human capital - of neoclassic origin, could be a limit in the sense of considering human capital as an exogenous growth factor, whose impact is reduced until it reaches the equilibrium stationary condition.

Nevertheless, validating also the endogenous growth specifications counterbalances this limitation, validating successfully the analysed causal relation. These conclusive results regarding the relation between the human capital and the growth of the gross domestic product per capita open new opportunities and challenges for continuing and deepening the research, especially by the perspective of creating some complex indicators which can mirror more efficiently the reality of the educational system, more notably related to the quality of education and to the efficiency of investing in education.

At the same time, the analysis can also be developed on new specifications of the growth regressions, which could be improved and thus, could become more relevant, by comprising a greater number of countries within the research and involving new economic and social variable influence potentials, in parallel with variables which reflect the environment, as well as the political environment, respectively respecting the human rights.

\section{Bibliography}

1. Andrei, T., Stancu, S., Pele, D.T. (2002) Statistica - Teorie si aplicatii, Editia a doua, Editura Economica, Bucuresti. 
2. Barro, R. (2000) „Education and Economic Growth”,International Handbook on the Economics of Education.

3. Barro, R., Lee, J.W. (2011) ,A New Data Set of Educational Attainment in the World 1950-2010", NBER Working Paper 15902.

4. Hawkes, D., Ugur, M. (2012) "Evidence on the relationship between education, skills and economic growth in low-income countries: A systematic review", London: EPPI-Centre, Social Science Research Unit, Institute of Education, University of London.

5. Hanushek, E., Wöbmann, L. (2007) „Education Quality and Economic Growth", World Bank Working Paper 39511.

6. Islam, N. (1995) „Growth Empicics: A Panel Data Approach”, The Quarterly Journal of Economics, Vol. 110, No.4.

7. Mankiw, G., Romer, P., Weil, D. (1992) „A contribution to the Empirics of Economic Growth", The Quarterly Journal of Economics, Vol. 107, No.2.

8. Michaelowa, K. (2000) "Returns to Education in Low Income Countries: Evidence for Africa", Paper presented at the annual meeting of the Committee on Developing Countries of the German Economic Association, 30/6/00.

9. Mincer, J. (1995) „Economic Development, Growth of Human Capital, and the Dynamics of the Wage Structure",Discussion Paper Series No. 744, Columbia University.

10. Neagu, O. (2012) "Measuring the Effects of Human Capital on Growth in the case of Romania" Annals of Dunarea de JosUniversity, Galati, Fascicle I Economics and Applied Informatics, No 1/2012

11. Psacharopoulos, G. (2007b) „The returns to investment in higher education: Methods, Data and Policy Implications", Report on rates of return and funding models in Europe, Universidad Politecnica de Valencia, Centro de Estudios en Gestion de la Educacion Siperior.

12. Pritchett, L. (2001) „Where Has All the Education Gone?”, The World Bank Economic Review, Vol. 15, No. 3.

***Barro \& Lee Databases (2012)

***Eurostat (2012), Statistics, Education, PISA.

***United Nations, Population Division (2012) World Population Prospects, www.un.org 
Pribac, L., Anghelina, A., (2015)

Human capital - the effects of education on economic growth within the European Union

Annex 1

The values obtained for the coefficient of human capital variables

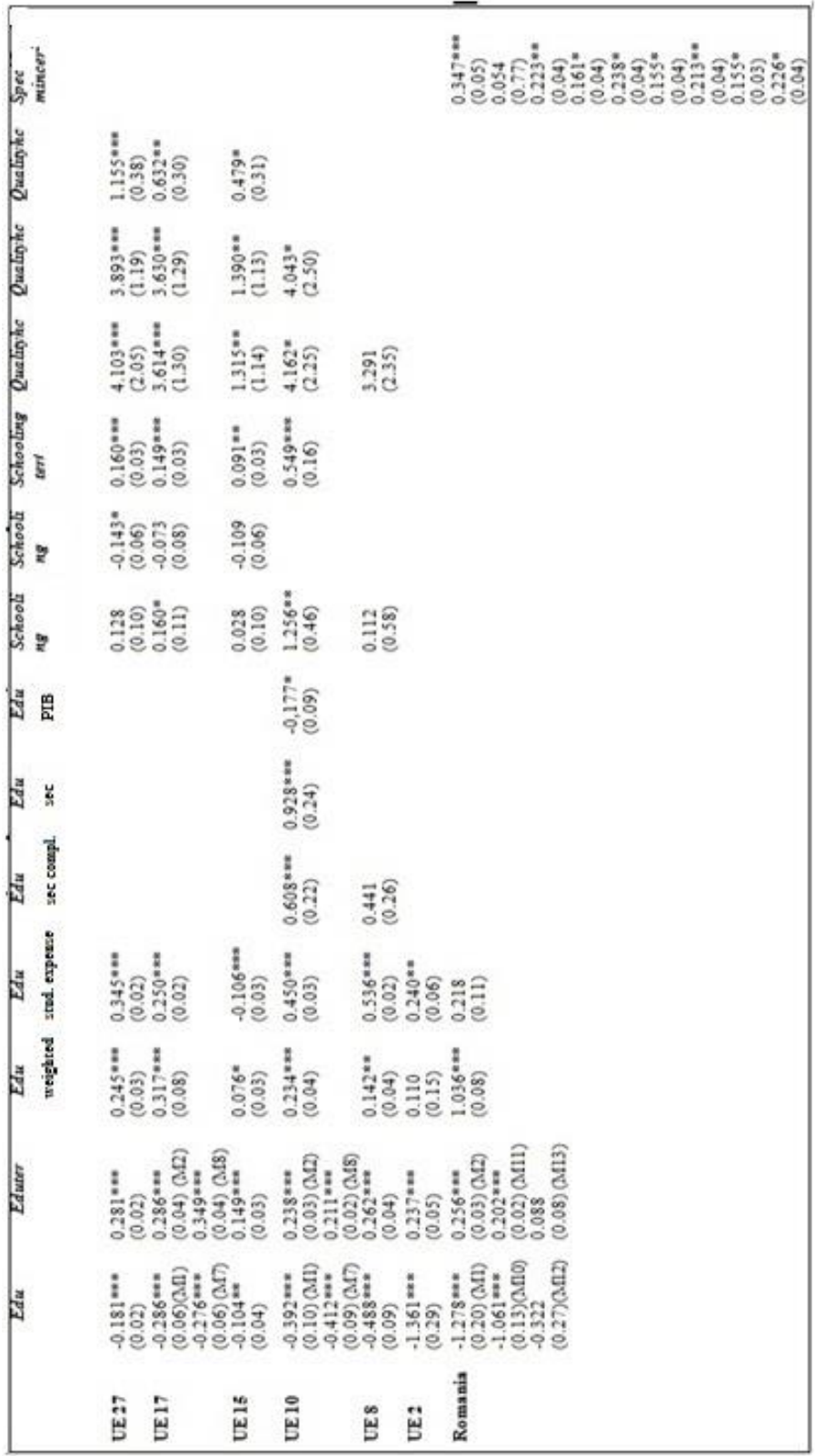

Source: My research - using the statistical programme Stata 